\title{
Direct genetic characterization of Toxoplasma gondii from clinical samples from Denmark : not only genotypes II and III
}

\author{
Jokelainen, $\mathrm{P}$.
}

2018-03

Jokelainen , P , Murat , J-B \& Nielsen , H V 2018 , ' Direct genetic characterization of Toxoplasma gondii from clinical samples from Denmark : not only genotypes II and III ', European Journal of Clinical Microbiology \& Infectious Diseases, vol. 37 , no. 3 , pp. 579-586 . https://doi.org/10.1007/s10096-017-3152-z

http://hdl.handle.net/10138/300581

https://doi.org/10.1007/s10096-017-3152-z

publishedVersion

Downloaded from Helda, University of Helsinki institutional repository.

This is an electronic reprint of the original article.

This reprint may differ from the original in pagination and typographic detail.

Please cite the original version. 


\title{
Direct genetic characterization of Toxoplasma gondii from clinical samples from Denmark: not only genotypes II and III
}

\author{
P. Jokelainen ${ }^{1,2,3}$ (I) J-B. Murat ${ }^{4,5} \cdot$ H. V. Nielsen ${ }^{1}$
}

Received: 6 October 2017 / Accepted: 24 November 2017 / Published online: 3 December 2017

(C) Springer-Verlag GmbH Germany, part of Springer Nature 2017

\begin{abstract}
Genetic variation within Toxoplasma gondii can have both clinical and epidemiological significance, while the genotypes circulating in many parts of the world, including the Nordic country Denmark, are still unknown. We genetically characterized T. gondii strains that had been detected in human clinical samples in Denmark in 2011-2016. Samples that had tested positive for T. gondii DNA and had a quantification cycle value $<33$ were included in this study and subjected to direct genetic characterization of $T$. gondii based on length-polymorphism of 15 microsatellite markers. A total of 23 DNA samples from 22 individual patients were analyzed. The results were consistent with genotype II with 15/15 markers amplified from seven samples from the central nervous system (CNS) including two samples from one patient, four ocular samples, and one unspecified sample; with genotype III with 15/15 markers amplified from two ocular samples; with genotype Africa 1 with 15/15 markers amplified from one amniotic fluid sample and from one CNS-sample; with atypical genotype with 15/15 markers amplified from one CNSsample and with 11/15 markers amplified from one CNS-sample; and with HG12-like genotype with 9/15 markers amplified from one CNS-sample. Genotype II, which is endemic in Europe, was predominant, but more than a third of the successfully genotyped strains were non-type-II. The possibility that clinical toxoplasmosis is caused by a strain that is not considered endemic to the region is definitely not negligible.
\end{abstract}

Electronic supplementary material The online version of this article (https://doi.org/10.1007/s10096-017-3152-z) contains supplementary material, which is available to authorized users.

P. Jokelainen pijo@ssi.dk

$\triangle$ H. V. Nielsen hvn@ssi.dk

1 Laboratory of Parasitology, Department of Bacteria, Parasites \& Fungi, Infectious Disease Preparedness, Statens Serum Institut, Artillerivej 5, DK-2300 Copenhagen S, Denmark

2 University of Helsinki, Helsinki, Finland

3 Estonian University of Life Sciences, Tartu, Estonia

4 National Reference Centre for Toxoplasmosis, Biological Resource Center for Toxoplasma, Laboratoire de Parasitologie et de Mycologie, Centre Hospitalier Universitaire de Limoges, Limoges, France

5 INSERM, UMR_S 1094, Neuroépidémiologie Tropicale, Université de Limoges, Limoges, France

\section{Introduction}

Many aspects, including characteristics of both the host and the parasite, affect the outcome of infection with Toxoplasma gondii [1]. Genotype II strains of T. gondii appear to predominate in Europe: in France, more than 90\% of strains have been genotype II strains [2]. Genotype II strains are nonvirulent for most strains of laboratory mice [1] but able to cause clinical disease and deaths in humans [3-6] as well as in animal hosts [7-13]. Genotype III has been described as the second most common genotype in Europe [4]. Strains that are atypical from the European point of view and mostly found in South America have appeared more virulent [14-19], and introduction of such highly virulent $T$. gondii strains to Europe has been considered an emerging biological risk [20].

The Laboratory of Parasitology of Statens Serum Institut (SSI) is located in Copenhagen, Denmark, and functions as the national $T$. gondii reference laboratory offering a range of indirect and direct methods to diagnose $T$. gondii infections. During 2003-2016, the annual mean number of human clinical samples that were tested for presence of $T$. gondii DNA was 79 [21]. The majority of the samples were from the central nervous system (CNS) or ocular samples, and $8.6 \%$ of them 
tested positive. However, the genotypes causing clinical disease - based on the submitted samples including a wide variety of manifestations from lymphadenopathy to congenital toxoplasmosis [21, 22] — have been unknown. In 2011, a small pilot study applying $T$. gondii genotyping to six clinical samples found genotype II strain in two samples and genotype Africa 1 strain in one sample (H. V. Nielsen and D. Ajzenberg, unpublished data). In this study, we genetically characterized T. gondii strains detected in human clinical samples in Denmark in 2011-2016.

\section{Materials and methods}

\section{Ethics statement}

We investigated archived surplus of DNA samples that had been extracted from clinical samples. The study was retrospective and did not involve any contact with the patients. The samples and data were coded and handled confidentially, and are presented so that the individual patients cannot be identified.

\section{Inclusion criteria}

Our sampling frame was DNA samples routinely extracted from various human clinical samples submitted to the Danish national $T$. gondii reference laboratory, SSI, for diagnostic real-time PCR for detecting $T$. gondii DNA. To our knowledge, all or most PCR diagnostics for suspected toxoplasmosis is referred to our laboratory, i.e. the sampling frame was of nationwide scope. The diagnostic real-time PCR targeted the repetitive 529 bp DNA fragment [23]. We included DNA samples that had tested positive for $T$. gondii DNA in 2011-2016 with a quantification cycle $\left(\mathrm{C}_{\mathrm{q}}\right)$ value $<33$ and that were available as surplus material for this study.

\section{Direct genetic characterization of $T$. gondii}

The genetic characterization method that we used is based on length-polymorphism of 15 microsatellite markers [24]. Each run included DNA of the ME49 strain that had been extracted from brain tissue of a laboratory mouse as a positive control and reference to ensure that the expected fragment sizes were retrieved. Sample ID 2 was diluted 1:4 and sample ID 14 was diluted 3:2 due to limited volume available, other samples were subjected to the analysis directly. The analysis was performed blinded.

\section{Distance analysis (tree)}

To evaluate the position of strains genotyped with all 15 markers amplified in the present study in relation to a selection of reference strains and strains isolated worldwide, a neighbor-joining analysis of the 15 microsatellite markers was repeated for 1,000 bootstrap replicates and displayed as an unrooted tree drawn using MEGA version 6 . The strains included in the tree were selected to represent the worldwide diversity of $T$. gondii genotypes currently known, as well as to increase the visible diversity of the haplogroups to which strains from the present study belonged. The results of genetic characterization for the 70 strains used in the distance analysis are shown in Online Resource 1.

\section{Statistical analyses}

We used the open-source software OpenEpi [25] to calculate 95\% confidence intervals ( $95 \% \mathrm{CI}$, Mid- $P$ exact) for the proportions and for two-by-two table comparisons (two-tailed $P$ value, Mid- $P$ exact). Further statistical analyses were performed with Stata 13.1 (StataCorp, College Station, TX, USA). $P$-values ( $P$-values, two-tailed, Mid- $P$ exact, from two-by-two table comparisons; $P$-values as provided by Stata, $P>|\mathrm{z}|$ and Prob $>$ chi2) $<0.05$ were considered statistically significant.

For the statistical analyses, we dichotomized the successful genotyping results into type-II or -III and non-type-II nor -III (outcome) and included only one result per patient. We considered amplification of $\geq 5$ of the eight genotyping markers (TUB2, W35, TgM-A, B18, B17, M33, IV.1, XI.1) as successful genotyping. The variables evaluated were dichotomous: age group of the patient ( $<55$ years or $\geq 55$ years), gender of the patient (female or male), whether the patient was reported to be immunocompromised, whether the sample was from the CNS or an ocular sample, and sampling period (2011-2013 or 2014-2016). Each variable was first evaluated using a twoby-two table and univariable regression analysis. Building multivariable regression models was attempted by including all variables followed by backward elimination of those with $P$-values $>0.05$ that did not act as confounders. The predictive ability of the models with significant variable(s) was evaluated as the area under the receiver operating characteristic (ROC) curve. Maximum area under the ROC curve would be 1.0, while an area of 0.5 would indicate no predictive ability at all.

Data availability All data generated and analyzed during this study are included in this published article and its supplementary information files.

\section{Results}

A total of 544 samples were received at the laboratory for the real-time PCR for T. gondii DNA in 2011-2016. Of them, 51 $(9.4 \%, 95 \%$ CI $7.1-12.1)$ had tested positive. This proportion testing positive was not statistically different from the 
proportion testing positive in 2003-2016 (8.6\% ; 95\% CI, 7.110.4; $P$-value 0.6082 ) [21]. The $\mathrm{C}_{\mathrm{q}}$-values of the positive samples ranged from 14.62 to 40.89 (mean, 30.19; median, 31.78); few with a high $\mathrm{C}_{\mathrm{q}}$-value had a comment 'doubtful'. The $\mathrm{C}_{\mathrm{q}}$-values were unavailable for four positive samples. Altogether, 27 samples had $\mathrm{C}_{\mathrm{q}}$-value $<33$. Four of these samples were not available as surplus for this study, thus the final sample size became 23 samples, which was $4.2 \%$ of all samples received at the laboratory for the real-time PCR for T. gondii DNA during 2011-2016.

The 23 DNA samples included in this study were from 22 individual patients. The $\mathrm{C}_{\mathrm{q}}$-values ranged from 15.18 to 32.33 (mean, 25.66; median, 25.55). The age of the patients ranged from 24 years to 81 years (mean, 59.8 years; median, 61.5 years), and $12(55 \%)$ of them were female and 10 (45\%) were male. The mean age was 59.9 years among the females and 59.7 years among the males; the median age was 63.5 years among the females and 60.5 years among the males. All patients except one had a Danish civil registration number. Twelve samples, including two samples from one patient, were from 2011 to 2013, and 11 samples were from 2014 to 2016. Eleven of the samples, including two samples from one patient, were CNS-samples, nine of the samples were ocular samples, and one was amniotic fluid. The sample material was unspecified for two samples. The CNS-samples were from individuals with a mean age of 58.8 years, and the ocular samples were from individuals with a mean age of 66.1 years. Information about immunostatus was not consistently provided. Six $(27 \%)$ of the patients were reportedly immunocompromised; the samples from them were CNSsamples. By contrast, all ocular samples and the amniotic fluid sample were from individuals not reported as immunocompromised.

The results of genetic characterization of $T$. gondii from the 23 clinical samples as well as of the reference and control strain ME49 are shown in Table 1. All 15/15 markers [24] were amplified from 17 samples (Table 1, Fig. 1). No results were obtained from one ocular sample and one unspecified sample. The samples yielding no results were both from the more recent sampling period 2014-2016; the mean number of markers amplified was 13 from samples from 2011 to 2013 and 11 from samples from 2014 to 2016 . Genotyping was successful ( $\geq 5$ of the 8 genotyping markers amplified) from altogether 19 samples, including two samples from one patient: from all 17 samples with $\mathrm{C}_{\mathrm{q}}$-value $<30$ (including the two samples that had to be diluted) and from two out of six samples with $\mathrm{C}_{\mathrm{q}}$-value $\geq 30$ and $<33$ (Table 1). Altogether, nine markers were amplified from the sample diluted 1:4 and all 15 markers from the sample diluted $3: 2$. There was no evidence of mixed infections with several genotypes. Two of the results were identical and those two samples were from the same patient.
Genotype II was the most common genotype identified: of the 18 patients with the parasite strain successfully genotyped, genotype II strain was found in $11(61 \%)$. Results consistent with genotype II, with 15/15 markers amplified, were obtained from seven CNS-samples (including two samples from one patient), four ocular samples, and one unspecified sample. In addition, results suggestive of genotype II, with fewer markers amplified, were obtained from two ocular samples. Results consistent with genotype III, with 15/15 markers amplified, were obtained from two ocular samples. These two genotype III strains were very close to each other, differing by one dinucleotide on marker N61.

Results consistent with genotype Africa 1, with 15/15 markers amplified, were obtained from one CNS-sample and from one amniotic fluid sample. Results revealing atypical genotypes, with 15/15 and 11/15 markers amplified, were obtained from two CNS-samples. Results very close to those from strains identified as HG12 but with an unusual type I allele on marker TUB2, with 9/15 markers amplified, were obtained from one CNS-sample.

The statistical analysis included successful genotyping results from 18 patients: $13(72 \%)$ type-II or -III, and 5 (28\%) non-type-II nor -III results (Table 2). The three patients who were $<50$ years old all had a non-type-II nor -III result, and four out of five patients who were $<55$ years old had a non-type-II nor -III result (two-bytwo table comparison, $P$-value 0.0078 , Table 2 ). Based on the results of logistic regression analyses, estimated using data from the 18 patients, the only significant risk factor for having non-type-II nor -III strain was younger age. Based on the results of the univariable logistic regression model, patients who were < 55 years old had 48 (95\% CI, 2.4-958.2; $P$-value 0.011) times higher odds to have nontype-II nor -III strain than did patients who were $\geq 55$ years of age. The test of the overall model (Prob > chi2) was 0.0024 , indicating the model was statistically significant. The area under the ROC curve was 0.86 , suggesting the model would have good predictive power.

\section{Discussion}

The results of this study offer support for the predominance of $T$. gondii genotype II strains in Europe [2, 5, 6]. However, the results also highlight that genotype II strains are not the only ones detected in clinical samples in this region: in this study, almost $40 \%$ of the successfully genotyped strains were non-type-II. Finding two genotype III strains is not the most demonstrative, as strains of genotype III have been found in Europe, as the second most common genotype [4], as well as on other continents [26-29]. In this study using clinical samples from Denmark, Africa 1 genotype was as common as genotype III, and one strain of Africa 1 
Table 1 Genetic characterization of Toxoplasma gondii from 23 clinical samples from Denmark

\begin{tabular}{|c|c|c|c|c|c|c|c|c|c|c|c|c|c|c|c|c|c|}
\hline \multirow[t]{2}{*}{ Sample ID } & \multirow[t]{2}{*}{$\mathrm{C}_{\mathrm{q}}$-value } & \multicolumn{15}{|c|}{ Microsatellite markers } & \multirow[t]{2}{*}{ Genotype $^{a}$} \\
\hline & & $T U B 2 *$ & $W 35^{*}$ & $\operatorname{Tg} M-A^{*}$ & $B 18^{*}$ & $B 17^{*}$ & $M 33 *$ & $I V .1^{*}$ & $X I .1 *$ & M48 & $M 102$ & N60 & $N 82$ & $A A$ & $N 61$ & $N 83$ & \\
\hline 1 & 25.55 & 289 & 242 & 207 & 158 & 336 & 169 & 274 & 356 & 235 & 174 & 145 & 115 & 287 & 95 & 310 & II $15 / 15$ \\
\hline 2 & 29.17 & 291 & NA & 211 & 160 & 336 & 169 & 274 & 362 & NA & NA & 142 & NA & NA & 93 & NA & $\begin{array}{l}\text { close to HG12 } \\
9 / 15\end{array}$ \\
\hline 3 & 31.42 & 291 & NA & 205 & 160 & 336 & NA & 274 & NA & NA & 166 & 147 & 111 & 271 & 87 & 306 & Atypical 11/15 \\
\hline 4 & 15.18 & 289 & 242 & 207 & 158 & 336 & 169 & 274 & 356 & 229 & 176 & 142 & 111 & 259 & 93 & 310 & II $15 / 15$ \\
\hline 5 & 27.83 & 289 & 242 & 207 & 158 & 336 & 169 & 274 & 356 & 213 & 174 & 140 & 111 & 267 & 95 & 312 & II $15 / 15$ \\
\hline 6 & 32.33 & 289 & NA & NA & 158 & NA & 169 & NA & NA & 216 & NA & NA & NA & NA & 91 & 308 & (II 6/15) \\
\hline 7 & 21.42 & 289 & 242 & 207 & 158 & 336 & 169 & 274 & 356 & 211 & 176 & 140 & 109 & 273 & 87 & 312 & II $15 / 15$ \\
\hline 8 & 19.19 & 291 & 248 & 205 & 160 & 342 & 165 & 274 & 354 & 225 & 166 & 147 & 111 & 275 & 89 & 306 & Africa 1 15/15 \\
\hline 9 & 24.77 & 289 & 242 & 207 & 158 & 336 & 169 & 274 & 356 & 227 & 172 & 138 & 111 & 279 & 85 & 308 & II $15 / 15^{\mathrm{b}}$ \\
\hline 10 & 23.60 & 289 & 242 & 207 & 158 & 336 & 169 & 274 & 356 & 227 & 172 & 138 & 111 & 279 & 85 & 308 & II $15 / 15^{b}$ \\
\hline 11 & 23.40 & 289 & 242 & 207 & 158 & 336 & 169 & 274 & 356 & 229 & 176 & 142 & 111 & 261 & 97 & 310 & II $15 / 15$ \\
\hline 12 & 24.73 & 289 & 242 & 207 & 158 & 336 & 169 & 274 & 356 & 215 & 178 & 140 & 111 & 269 & 95 & 312 & II $15 / 15$ \\
\hline 13 & 28.39 & 289 & 242 & 205 & 160 & 336 & 165 & 278 & 356 & 213 & 190 & 147 & 111 & 267 & 87 & 312 & III 15/15 \\
\hline 14 & 16.91 & 289 & 242 & 207 & 158 & 336 & 169 & 274 & 356 & 233 & 174 & 142 & 111 & 267 & 87 & 310 & II $15 / 15$ \\
\hline 15 & 32.02 & NA & NA & NA & NA & NA & NA & NA & NA & NA & NA & NA & NA & NA & NA & NA & (NA) \\
\hline 16 & 24.03 & 289 & 242 & 207 & 158 & 336 & 169 & 274 & 356 & 211 & 176 & 271 & 113 & 271 & 93 & 308 & II $15 / 15$ \\
\hline 17 & 31.13 & NA & NA & NA & NA & NA & NA & NA & NA & NA & NA & NA & NA & NA & NA & NA & (NA) \\
\hline 18 & 26.88 & 291 & 248 & 205 & 160 & 342 & 165 & 274 & 354 & 229 & 166 & 147 & 111 & 271 & 89 & 306 & Africa 1 15/15 \\
\hline 19 & 31.95 & 289 & 242 & 207 & 158 & 336 & 169 & 274 & 356 & 249 & 178 & 149 & 111 & 259 & 99 & 314 & II $15 / 15$ \\
\hline 20 & 21.92 & 291 & 242 & 205 & 162 & 336 & 165 & 274 & 356 & 227 & 176 & 147 & 111 & 275 & 89 & 304 & Atypical 15/15 \\
\hline 21 & 18.76 & 289 & 242 & 205 & 160 & 336 & 165 & 278 & 356 & 213 & 190 & 147 & 111 & 267 & 89 & 312 & III 15/15 \\
\hline 22 & 30.78 & NA & NA & 207 & NA & NA & 169 & NA & NA & NA & 178 & NA & NA & NA & NA & NA & (II 3/15) \\
\hline 23 & 28.93 & 289 & 242 & 207 & 158 & 336 & 169 & 274 & 356 & 231 & 174 & 142 & 111 & 263 & 89 & 314 & II $15 / 15$ \\
\hline ME49 & & 289 & 242 & 207 & 158 & 336 & 169 & 274 & 356 & 215 & 174 & 142 & 111 & 265 & 91 & 310 & II $15 / 15$ \\
\hline
\end{tabular}

$C_{q^{-}}$value quantification cycle value, $N A$ not amplified

Sample ID 2 was diluted 1:4 and sample ID 14 was diluted 3:2, other samples were subjected to the analysis directly

*Genotyping marker

${ }^{\text {a }}$ Genotype in parentheses if $<5$ of the 8 genotyping markers amplified

${ }^{\mathrm{b}}$ Identical results; the two samples were from the same patient

${ }^{\mathrm{c}}$ Reference strain

genotype was also found in the pilot study. We also found one strain of a HG12-like genotype, which shared similarities to HG12 strains that represent the fourth clonal lineage in North America [30]. One atypical genotype identified with 15/15 markers amplified appeared quite far from known genotypes and related to both Caribbean and African strains (Fig. 1). All but one of the patients included in this study had a Danish civil registration number, which tells that they were registered in the national register on the grounds of birth, due to immigration and stay of over 3 months, or for processing of taxes or pension. Where the strains that we characterized in this study had been acquired remains unknown. Nevertheless, it should be also noted that naming genotypes based on geographical region may be misleading, particularly as the global map of characterized strains still has large areas with no data [2]. Our understanding of the genetic variation within $T$. gondii by geographical location is far from complete.

Four out of five patients who were $<55$ years old had a nontype-II nor -III result (Table 2). This suggests that younger generations seen by the Danish health care system could have been exposed to a wider variety of strains, perhaps due to different risk profile or more diverse background. The mean age among the patients included in this study was 59.8 years, and it is noteworthy that the ocular samples were from individuals with a mean age of 66.1 years. This was higher than the mean age of 53.3 years among 20 patients with ocular toxoplasmosis in a study from France [5] and the mean age of 56.0 years among four patients with ocular toxoplasmosis in a study from Germany [6]. These observations suggest that 

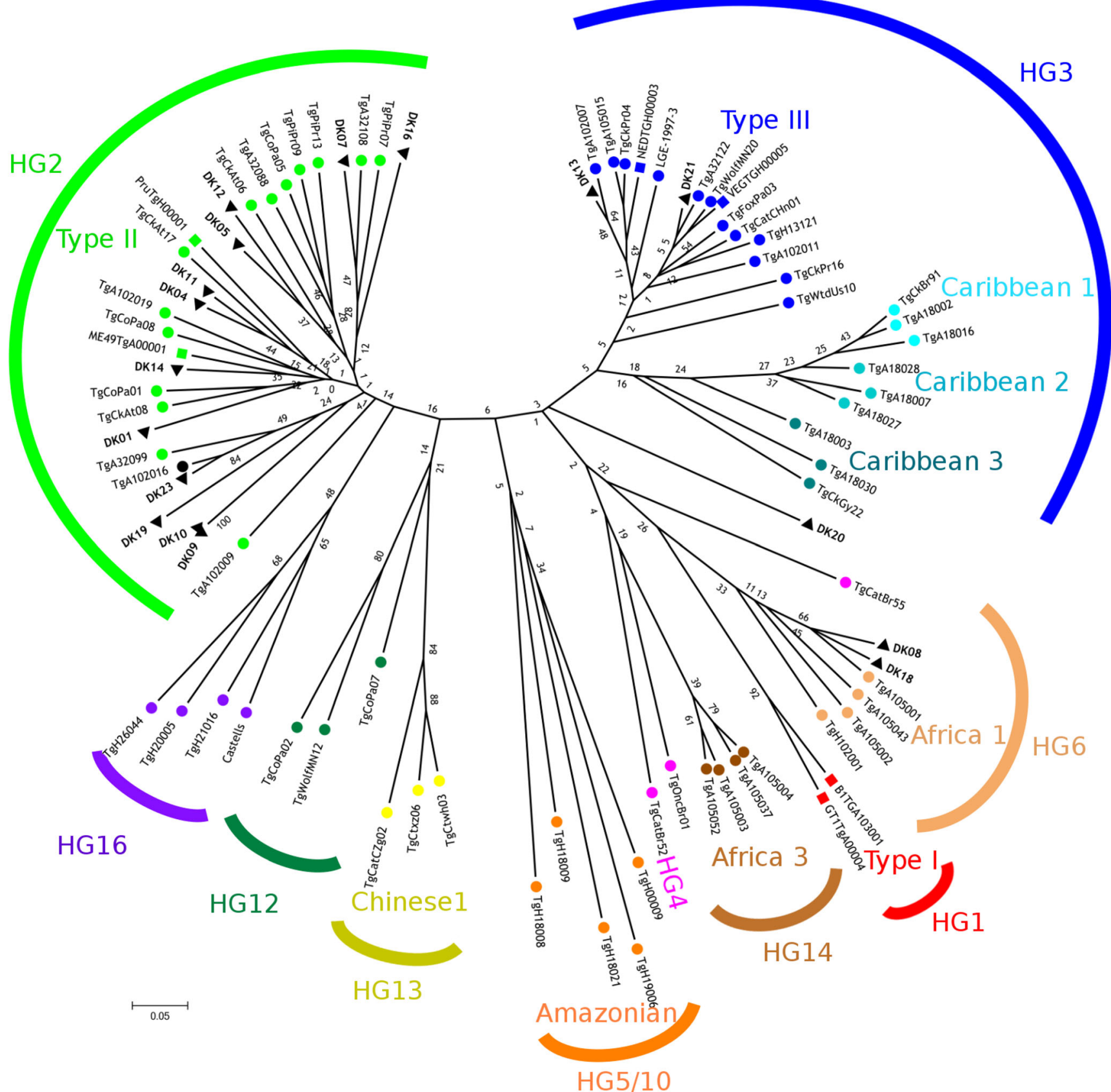

Fig. 1 Neighbor-joining clustering of Toxoplasma gondii strains, based on 15 microsatellite markers: black triangles are 17 strains with 15/15 markers amplified from clinical samples from Denmark; red, green, and

dark blue squares are reference strains of genotype I, genotype II, and genotype III, respectively

clinical toxoplasmosis, and in particular ocular toxoplasmosis, may be of particular and perhaps underemphasized relevance for individuals who are over 50 years of age. The observation that all ocular samples included in our study were from adult individuals who were not reported as immunocompromised is suggestive of acquired ocular toxoplasmosis. All samples from reportedly immunocompromised individuals were CNS-samples, indicating that $T$. gondii remains a relevant opportunistic threat [31].
The multilocus genetic characterization method [24] that we used in this study allowed discrimination between T. gondii strains at two levels: genotyping and fingerprinting, i.e., insight into genetic variation also beyond the level of genotyping. The genetic characterization was direct, i.e. without preceding bioassay or cell culture step that could introduce selection. We detected no mixed infections with more than one strain. The two samples from one patient were correctly identified as identical (Table 1). None of the other results were 
Table 2 The successfully genotyped Toxoplasma gondii strains from human clinical samples from 18 patients in Denmark, 2011-2016, categorized as type-II or -III strains and non-type-II nor -III strains, shown by gender, age, reported immunostatus, sample material, and sampling period

\begin{tabular}{|c|c|c|c|c|c|c|}
\hline \multirow[t]{2}{*}{ Variable } & \multirow[t]{2}{*}{ Number of patients } & \multirow{2}{*}{$\begin{array}{l}\text { Number of patients, } \\
\text { type-II or -III }\end{array}$} & \multirow{2}{*}{$\begin{array}{l}\text { Number of patients, } \\
\text { non-type-II nor -III }\end{array}$} & \multicolumn{3}{|c|}{ Proportion non-type-II nor -III } \\
\hline & & & & $\%$ non-type-II nor -III & $95 \%$ confidence interval & $P$-value \\
\hline Female & 10 & 7 & 3 & 30 & $8-62$ & 0.8431 \\
\hline Male & 8 & 6 & 2 & 25 & $4-61$ & \\
\hline$<55$ years old & 5 & 1 & 4 & 80 & $33-99$ & $0.0078^{*}$ \\
\hline$\geq 55$ years old & 13 & 12 & 1 & 8 & $0.4-32$ & \\
\hline $\begin{array}{l}\text { Not reported as } \\
\text { immunocompromised }\end{array}$ & 12 & 9 & 3 & 25 & $7-54$ & 0.7367 \\
\hline Immunocompromised & 6 & 4 & 2 & 33 & $6-74$ & \\
\hline Ocular sample ${ }^{\mathrm{a}}$ & 6 & 6 & 0 & 0 & $0-39$ & 0.1154 \\
\hline $\begin{array}{l}\text { Sample from the central } \\
\text { nervous system }{ }^{\mathrm{a}}\end{array}$ & 10 & 6 & 4 & 40 & $14-71$ & \\
\hline Sample from 2011 to 2013 & 10 & 7 & 3 & 30 & $8-62$ & 0.8431 \\
\hline Sample from 2014 to 2016 & 8 & 6 & 2 & 25 & $4-61$ & \\
\hline Total & 18 & 13 & 5 & 28 & $11-51$ & \\
\hline
\end{tabular}

95\% confidence interval, Mid- $P$ exact

$P$-value, from two-by-two table comparison, two-tailed, Mid- $P$ exact

* Statistically significant difference

${ }^{\text {a }}$ Other sample materials not shown

identical with each other, indicating that the infections were from different, separate point sources.

The majority of the results were full results, with $15 / 15$ markers amplified, illustrating that the method is suitable for direct use on clinical samples, including clinical samples that have been archived frozen. The DNA samples had been stored frozen, some of them for years, which may have caused DNA degradation but was not expected nor observed to have a major effect on the results [32]. All samples with $\mathrm{C}_{\mathrm{q}}$-value $<30$ were successfully genotyped, whereas the success rate was $33 \%$ from samples with $\mathrm{C}_{\mathrm{q}}$-value $\geq 30$ and $<33$ (Table 1). At least in the setting at SSI, clinical samples that are positive for T. gondii DNA with $\mathrm{C}_{\mathrm{q}}$-value $<30$ can be encouraged for direct genotyping using this method. As this cut-off is close to the mean and median of $\mathrm{C}_{\mathrm{q}}$-values of all samples that were positive for T. gondii DNA, this would mean that about half of the positive samples could be genotyped.

The current routine $T$. gondii diagnostics are done only to the species level. Routinely characterizing the $T$. gondii strains that are detected would yield baseline data that could prove useful for detecting outbreaks, for source attribution, and for preparedness to identify strains that are imported or newly emerging to a region, or that might warrant different clinical management. The results of this study highlight that clinical toxoplasmosis can be caused by a genotype that is not considered endemic to the region.

The results of this study add to the knowledge on molecular and clinical epidemiology of $T$. gondii, although with major limitations. Our results fill a geographical gap and contribute to the current knowledge on global genetic variation within $T$. gondii, but the sample is a referralbiased tip of the iceberg of clinical $T$. gondii infections in humans, likely a dead-end host species from the parasite point of view. Based on the results of this study, we cannot conclude which of the strains could be local; the infections were diagnosed in Denmark but their origins and sources remain unknown. It is possible that the Africa 1 genotype strains were acquired in Africa, or that the HG12-like genotype was acquired in North America. However, it is also possible that they were acquired in Denmark, which thus far has no genotype named after it. The important point is that regardless of the origin of the strains characterized in our study, they were causing clinical disease and they were diagnosed in Denmark. Epidemiology of T. gondii has a global scale, which is crucial to take into account when addressing the disease burden of toxoplasmosis [22, 33-37]. Because T. gondii infection can be acquired at any point of the human lifespan and clinical toxoplasmosis can be due to primary or reactivated infection, the source and origin of the infection often remain unknown. Region of origin or longer stay may be of epidemiological relevance, but people travel, move, and migrate. Moreover, foodborne infections may be acquired from imported food items. For example, atypical $T$. gondii genotypes have been imported to Europe in horse meat $[19,38]$. Studies on local animal hosts that likely acquire $T$. gondii infections from local sources and that might serve as infection source for other 
hosts would provide the needed baseline data on locally circulating strains.

Acknowledgements We thank Martin Ibenholdt Pedersen and Lis Lykke Wassmann for help with the DNA archives, Daniel Ajzenberg for teaching the genetic characterization method to PJ and to JBM, and members of the Burden of Disease of Toxoplasmosis in Denmark Working Group for discussing the work and commenting on the manuscript during its preparation.

\section{Compliance with ethical standards}

Conflict of interest The authors declare that they have no conflict of interest.

Informed consent For this type of study, formal consent is not required.

\section{References}

1. Maubon D, Ajzenberg D, Brenier-Pinchart MP, Dardé ML, Pelloux $\mathrm{H}$ (2008) What are the respective host and parasite contributions to toxoplasmosis? Trends Parasitol 24:299-303

2. Ajzenberg D (2015) 1995-2015: it is time to celebrate 20 years of (intensive) genotyping of Toxoplasma gondii strains. Future Microbiol 10:689-691

3. Ajzenberg D, Cogné N, Paris L, Bessières MH, Thulliez P, Filisetti D, Pelloux H, Marty P, Dardé ML (2002) Genotype of 86 Toxoplasma gondii isolates associated with human congenital toxoplasmosis, and correlation with clinical findings. J Infect Dis 186: 684-689

4. Ajzenberg D, Yera H, Marty P, Paris L, Dalle F, Menotti J, Aubert $\mathrm{D}$, Franck J, Bessières MH, Quinio D, Pelloux H, Delhaes L, Desbois N, Thulliez P, Robert-Gangneux F, Kauffmann-Lacroix C, Pujol S, Rabodonirina M, Bougnoux ME, Cuisenier B, Duhamel C, Duong TH, Filisetti D, Flori P, Gay-Andrieu F, Pratlong F, Nevez G, Totet A, Carme B, Bonnabau H, Dardé ML, Villena I (2009) Genotype of 88 Toxoplasma gondii isolates associated with toxoplasmosis in immunocompromised patients and correlation with clinical findings. J Infect Dis 199:1155-1167

5. Fekkar A, Ajzenberg D, Bodaghi B, Touafek F, Le Hoang P, Delmas J, Robert PY, Dardé ML, Mazier D, Paris L (2011) Direct genotyping of Toxoplasma gondii in ocular fluid samples from 20 patients with ocular toxoplasmosis: predominance of type II in France. J Clin Microbiol 49:1513-1517

6. Herrmann DC, Maksimov P, Hotop A, Groß U, Däubener W, Liesenfeld O, Pleyer U, Conraths FJ, Schares G (2014) Genotyping of samples from German patients with ocular, cerebral and systemic toxoplasmosis reveals a predominance of Toxoplasma gondii type II. Int J Med Microbiol 304:911-916

7. Herrmann DC, Wibbelt G, Götz M, Conraths FJ, Schares G (2013) Genetic characterisation of Toxoplasma gondii isolates from European beavers (Castor fiber) and European wildcats (Felis silvestris silvestris). Vet Parasitol 191:108-111

8. Jokelainen P, Isomursu M, Näreaho A, Oksanen A (2011) Natural Toxoplasma gondii infections in European brown hares and mountain hares in Finland: proportional mortality rate, antibody prevalence, and genetic characterization. J Wildl Dis 47:154-163

9. Jokelainen P, Nylund M (2012) Acute fatal toxoplasmosis in three Eurasian red squirrels (Sciurus vulgaris) caused by genotype II of Toxoplasma gondii. J Wildl Dis 48:454-457

10. Jokelainen P, Simola O, Rantanen E, Näreaho A, Lohi H, Sukura A (2012) Feline toxoplasmosis in Finland: cross-sectional epidemiological study and case series study. J Vet Diagn Investig 24:1115-1124

11. Jokelainen P, Vikøren T (2014) Acute fatal toxoplasmosis in a great spotted woodpecker (Dendrocopos major). J Wildl Dis 50:117-120

12. Prestrud KW, Åsbakk K, Mørk T, Fuglei E, Tryland M, Su C (2008) Direct high-resolution genotyping of Toxoplasma gondii in arctic foxes (Vulpes lagopus) in the remote arctic Svalbard archipelago reveals widespread clonal type II lineage. Vet Parasitol 158:121128

13. Spycher A, Geigy C, Howard J, Posthaus H, Gendron K, Gottstein B, Debache K, Herrmann DC, Schares G, Frey CF (2011) Isolation and genotyping of Toxoplasma gondii causing fatal systemic toxoplasmosis in an immunocompetent 10-year-old cat. J Vet Diagn Investig 23:104-108

14. Gilbert RE, Freeman K, Lago EG, Bahia-Oliveira LM, Tan HK, Wallon M, Buffolano W, Stanford MR, Petersen E; European Multicentre Study on Congenital Toxoplasmosis (EMSCOT) (2008) Ocular sequelae of congenital toxoplasmosis in Brazil compared with Europe. PLoS Negl Trop Dis 2:e277

15. de-la-Torre A, Sauer A, Pfaff AW, Bourcier T, Brunet J, SpeegSchatz C, Ballonzoli L, Villard O, Ajzenberg D, Sundar N, Grigg ME, Gomez-Marin JE, Candolfi E (2013) Severe south American ocular toxoplasmosis is associated with decreased Ifn- $\gamma / \mathrm{Il}-17 \mathrm{a}$ and increased Il-6/Il-13 intraocular levels. PLoS Negl Trop Dis 7:e2541

16. Sánchez V, de-la-Torre A, Gómez-Marín JE (2014) Characterization of ROP18 alleles in human toxoplasmosis. Parasitol Int 63:463-469

17. Pfaff AW, de-la-Torre A, Rochet E, Brunet J, Sabou M, Sauer A, Bourcier T, Gomez-Marin JE, Candolfi E (2014) New clinical and experimental insights into old world and neotropical ocular toxoplasmosis. Int J Parasitol 44:99-107

18. Demar M, Ajzenberg D, Maubon D, Djossou F, Panchoe D, Punwasi W, Valery N, Peneau C, Daigre JL, Aznar C, Cottrelle B, Terzan L, Dardé ML, Carme B (2007) Fatal outbreak of human toxoplasmosis along the Maroni River: epidemiological, clinical, and parasitological aspects. Clin Infect Dis 45:e88-e95

19. Sobanski V, Ajzenberg D, Delhaes L, Bautin N, Just N (2013) Severe toxoplasmosis in immunocompetent hosts: be aware of atypical strains. Am J Respir Crit Care Med 187:1143-1145

20. European Food Safety Authority (2014) Drivers of emerging risks and their interactions in the domain of biological risks to animal, plant and public health: a pilot study. EFSA supporting publication 2014:EN-588

21. Stensvold CR, Nielsen HV (2016) Selected parasite infections detected using the PCR method. EPI-NEWS 44. http://www.ssi.dk/ English/News/EPI-NEWS/2016/No\%2044\%20-\%202016.aspx. Accessed 26 September 2017

22. Nissen J, Jokelainen P, Stensvold CR, Trevisan C, Fuchs J, Burgdorf KS, Nielsen HV, Pires SM (2017) The disease burden of congenital toxoplasmosis in Denmark, 2014. PLoS One 12: $\mathrm{e} 0178282$

23. Homan WL, Vercammen M, De Braekeleer J, Verschueren H (2000) Identification of a 200 - to 300 -fold repetitive 529 bp DNA fragment in Toxoplasma gondii, and its use for diagnostic and quantitative PCR. Int J Parasitol 30:69-75

24. Ajzenberg D, Collinet F, Mercier A, Vignoles P, Dardé ML (2010) Genotyping of Toxoplasma gondii isolates with 15 microsatellite markers in a single multiplex PCR assay. J Clin Microbiol 48: 4641-4645

25. Dean AG, Sullivan KM, Soe MM (2016) OpenEpi: open source epidemiologic statistics for public health, version 3.01. www. openepi.com. Accessed 26 September 2017

26. Can H, Döşkaya M, Ajzenberg D, Özdemir HG, Caner A, İz SG, Döșkaya AD, Atalay E, Çetinkaya Ç, Ürgen S, Karaçalı S, Ün C, Dardé ML, Gürüz Y (2014) Genetic characterization of Toxoplasma 
gondii isolates and toxoplasmosis seroprevalence in stray cats of İzmir, Turkey. PLoS One 9:e104930

27. Dubey JP, Velmurugan GV, Rajendran C, Yabsley MJ, Thomas NJ, Beckmen KB, Sinnett D, Ruid D, Hart J, Fair PA, McFee WE, Shearn-Bochsler V, Kwok OC, Ferreira LR, Choudhary S, Faria EB, Zhou H, Felix TA, Su C (2011) Genetic characterisation of Toxoplasma gondii in wildlife from North America revealed widespread and high prevalence of the fourth clonal type. Int J Parasitol 41:1139-1147

28. Mercier A, Devillard S, Ngoubangoye B, Bonnabau H, Bañuls AL, Durand P, Salle B, Ajzenberg D, Dardé ML (2010) Additional haplogroups of Toxoplasma gondii out of Africa: population structure and mouse-virulence of strains from Gabon. PLoS Negl Trop Dis 4:e876

29. Zia-Ali N, Fazaeli A, Khoramizadeh M, Ajzenberg D, Dardé M, Keshavarz-Valian H (2007) Isolation and molecular characterization of Toxoplasma gondii strains from different hosts in Iran. Parasitol Res 101:111-115

30. Khan A, Dubey JP, Su C, Ajioka JW, Rosenthal BM, Sibley LD (2011) Genetic analyses of atypical Toxoplasma gondii strains reveal a fourth clonal lineage in North America. Int J Parasitol 41: 645-655

31. Bowen LN, Smith B, Reich D, Quezado M, Nath A (2016) HIVassociated opportunistic CNS infections: pathophysiology, diagnosis and treatment. Nat Rev Neurol 12:662-674

32. Delhaes L, Filisetti D, Brenier-Pinchart MP, Pelloux H, Yéra H, Dalle F, Sterkers Y, Varlet-Marie E, Touafek F, Cassaing S, Bastien $\mathrm{P}$ (2014) Freezing and storage at $-20{ }^{\circ} \mathrm{C}$ provides adequate preservation of Toxoplasma gondii DNA for retrospective molecular analysis. Diagn Microbiol Infect Dis 80:197-199

33. Havelaar AH, Haagsma JA, Mangen MJ, Kemmeren JM, Verhoef LP, Vijgen SM, Wilson M, Friesema IH, Kortbeek LM, van Duynhoven YT, van Pelt W (2012) Disease burden of foodborne pathogens in the Netherlands, 2009. Int J Food Microbiol 156:231-238

34. Havelaar AH, Kirk MD, Torgerson PR, Gibb HJ, Hald T, Lake RJ, Praet N, Bellinger DC, de Silva NR, Gargouri N, Speybroeck N, Cawthorne A, Mathers C, Stein C, Angulo FJ, Devleesschauwer B, World Health Organization Foodborne Disease Burden Epidemiology Reference Group (2015) World Health Organization global estimates and regional comparisons of the burden of Foodborne disease in 2010. PLoS Med 12:e1001923

35. van Lier A, Mcdonald SA, Bouwknegt M, EPI group, Kretzschmar ME, Havelaar AH, Mangen MJ, Wallinga J, de Melker HE (2016) Disease burden of 32 infectious diseases in the Netherlands, 20072011. PLoS One 11:e153106

36. Scallan E, Hoekstra RM, Mahon BE, Jones TF, Griffin PM (2015) An assessment of the human health impact of seven leading foodborne pathogens in the United States using disability adjusted life years. Epidemiol Infect 143:2795-2804

37. Smit GSA, Padalko E, Van Acker J, Hens N, Dorny P, Speybroeck N, Devleesschauwer B (2017) Public health impact of congenital toxoplasmosis and cytomegalovirus infection in Belgium, 2013: a systematic review and data synthesis. Clin Infect Dis 65:661-668

38. Pomares C, Ajzenberg D, Bornard L, Bernardin G, Hasseine L, Darde ML, Marty P (2011) Toxoplasmosis and horse meat, France. Emerg Infect Dis 17:1327-1328 